\title{
A Two-Stage Method to Optimize The Milk-Run System
}

\author{
Aslı Aksoy*, Nursel Öztürk
}

\begin{abstract}
In this competitive manufacturing environment, material transportation is an important topic for researchers and practical applications. This study presents a real life example of an automotive equipment manufacturer problem. The manufacturer has several depots to serve 54 milk-run suppliers and complained about the fluctuations of milk-run vehicles between work days and depots. The aim of this study is to develop a systematic approach to make milk-run system more stable for manufacturer. Therefore the systematic approach which consists of, the milk-run route optimization with mixed integer linear programming model, container loading heuristic to increase the utilization of milk-run vehicles and time interval assignment heuristic to avoid coincidence of milk-run vehicles at the depots, is suggested to get over existing problems of a manufacturer.
\end{abstract}

Index Terms - Container loading problem Logistics optimization, Milk-run system, Mixed integer linear programming

\section{INTRODUCTION}

Nowadays, due to high competitive environment, marketing conditions become more volatile and requires lower cost and quick response. The worldwide shipping of goods significantly increase because of the globalization. The responsiveness to changing demand in this competitive global market become more crucial and time to market and product life cycle become shorter and the effect of price competition causes more pressure on companies. Logistics activities are one of the important factor of the supply chain management, and the companies should minimize their logistics cost and duration to have an important and strong role in the global market. Companies should provide high quality, lower costs and short response times while providing satisfactory and effective logistics services. The volatile market conditions cause more pressure on enterprises. The ongoing globalization of markets over the past decades accounts for an ever-increasing shipping volume of goods worldwide. Due to high competition and more demanding customers in the globalization market, the product life cycle and time to market become shorter, price competition becomes tougher, and the responsiveness to changing demand becomes more crucial.

In this paper, suggestions of a real life problem for an automotive equipment manufacturer are presented. This study focused on the production-logistics department of the manufacturer facility. The manufacturer has seven facilities (SUG1, SUG2, SUG3, SUG4, SUG5, SUG6, SUG7) and 26

\footnotetext{
Manuscript published September 30, 2016.

* Corresponding author

Asli Aksoy and Nursel Öztürk are with the Industrial Engineering

Department, Uludag University, Bursa, Turkey.

(e-mail: asliaksoy@uludag.edu.tr,nursel@uludag.edu.tr)
}

logistics depots located in those facilities. Manufacturer transports the finished products or semi-finished products, from suppliers to the depots with milk-run system and the manufacturer scheduled the milk-run vehicles daily, so the fluctuations between the workdays and the different depots are so high for the manufacturer. The fluctuations of the different facilities for different workdays can be seen in Figure 1.

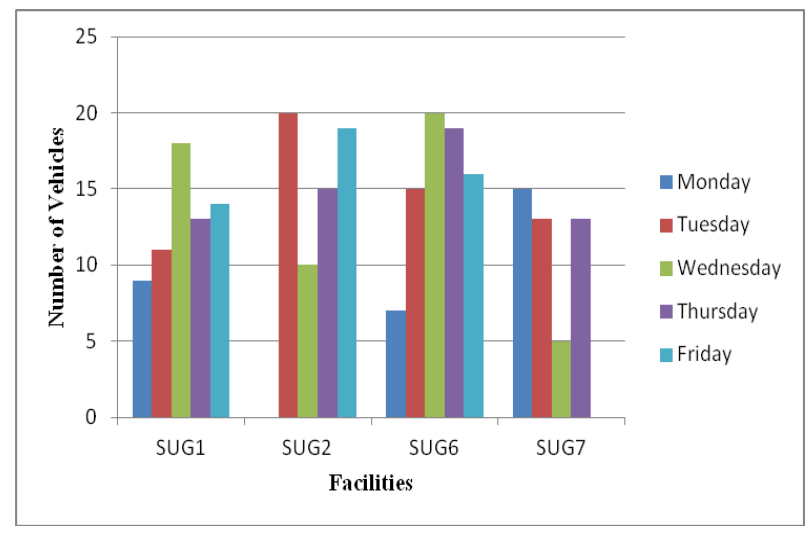

Fig. 1. Number of vehicles per facility for different workdays.

The milk run system of the manufacturer consists of 54 different suppliers with six different routes. The total route distance and the cycle time of the routes can be seen in Table 1.

TABLE 1. DATA OF MILK-RUN ROUTES

\begin{tabular}{|l|c|c|c|c|c|c|}
\hline & Route 1 & Route 2 & Route 3 & Route 4 & Route 5 & Route 6 \\
\hline $\begin{array}{l}\text { Number of } \\
\text { stops }\end{array}$ & 5 & 9 & 13 & 15 & 11 & 3 \\
\hline $\begin{array}{l}\text { Total } \\
\text { distance } \\
(\mathrm{km})\end{array}$ & 46.2 & 84 & 594 & 25.4 & 74.8 & 291 \\
\hline $\begin{array}{l}\text { Cycle time } \\
\text { (min) }\end{array}$ & 69 & 126 & 891 & 38 & 112 & 436 \\
\hline
\end{tabular}

The main problem of the manufacturer is the variability of the number of milk-run vehicles between work days and facilities. The manufacturer required more stable logistics schedule for milk-run vehicles. To get over existing problem, optimal milk-run routes are determined by mixed integer linear programming model and two different heuristic algorithms are developed to increase the container utilization and to assign the time interval of the related milkrun vehicle to the related depot. The details of the suggested methods and proposed models are presented in this study.

\section{LITERATURE REVIEW}

As logistics is an important factor to become a successful company, the overall goal of logistics is satisfying customers' demands with effective cost. Logistics and supply chain management is an activity to optimize material and information flows along the supply chain with 
the purpose of meeting the customer demand. The aim of logistics and supply chain management is extending the logistics upstream to the suppliers as well as downstream to final customers to gain the highest profit and spend the lowest cost [1].

Today, companies frequently carry out loading and distribution operations (planning and operative) based on experience of operators, without formal optimization (software) tools. This may lead to space waste inside the container. A further complication also occurs when a vehicle must serve more than one customer: it is necessary to optimize the delivery route in order to minimize driving distance and unloading work. Better routing and scheduling decisions can result in higher level of customer satisfaction because more customers can be served in a shorter time [2]. Several authors have studied delivery optimization which is known as the Vehicle Routing Problem (VRP). The loading optimization has also been widely studied and is known as the Container Loading Problem (CLP). However, very few papers have dealt with integrated approaches for loading and routing [3].

VRP has been introduced by Dantzig and Ramser in 1959, in its variant CVRP (Capacitated-VRP) [4]. In its classical formulation, the goal of the VRP is to serve a set of customers, having a known demand, minimizing the transportation cost, starting from a depot, where each vehicle comes back at the end of its route. Several variants of the problem have been formulated and studied and solving algorithms or heuristics have been proposed, but an exact algorithm that is able to solve instance with more than 50 customers does not exist [3], [5].

The capacitated vehicle routing problem (CVRP) is a fundamental problem in combinatorial optimization with wide-ranging applications in practice. It forms the core of logistics planning and has been extensively studied by the researchers [6], [7], [8].

The CVRP consists in determining a set of a maximum of $\mathrm{m}$ routes of minimum total cost, such that each route starts and ends at the depot, each customer is visited exactly once by exactly one vehicle, subject to the restriction that the total demand of any route does not exceed vehicle capacity [9].

A survey on the CVRP and variants is given by Toth and Vigo [8] and an overview of heuristics and metaheuristics may also be found in [10] and [11]. [12], [13] and [14] used tabu search heuristic algorithm to solve CVRP, [15] has reported similar results by applying simulated annealing to the CVRP. [16] proposed ant colony for VRPs and [17] presented an adaptation of the active guided evolution strategies metaheuristic for the CVRP. The results demonstrated that their suggested method is highly competitive. Genetic algorithms (GAs) have also been applied for the VRPs. [9] presented a GA for solving CVRP, which is mainly characterized by using identical vehicles at a central depot that will be optimally routed to supply customers with known demands.

The main purpose of the Container Loading Problem (CLP) is to increase space utilization ratio and reduce the cost. The effective space utilization becomes the main core of the problem. The kind of problem belongs to the combinatorial optimization problem. The problem focuses on how to achieve optimal space utilization in a limited space. CLP has already been studied by many scholars with different solution approaches. [18] first solved the problem by a two-phased method. [19] also used the phased method by constructing wall-build. [20] proposed a two-phase method, incorporating ant colony algorithm and GA, to improve the container utilization.

\section{PROPOSED APPROACH}

The scope of this study is limited to the optimization of milk-run routes of the automotive equipment manufacturer, the other logistics activities are out of scope. However, the developed tools are expected to be the models which can be adjusted for use of other logistics functions and other branch of the company.

The milk-run system of the manufacturer consists of 54 suppliers. Clustering analysis is used to grouping the suppliers. First of all suppliers are divided into two main clusters (in the same city or not) and divided to six subclasses by using Minitab. The Minitab tries to minimize the distances for the suppliers in the same class, while maximizing the distances between different classes. Figure 2 includes the dendrogram of the two main clusters: in the same city (a) with four sub-classes, in different city with two sub-classes (b).

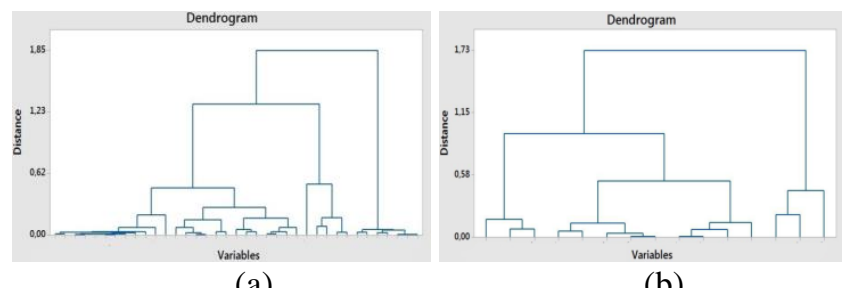

(a)

(b)

Fig. 2. Cluster analysis of the suppliers

\section{A. Mixed Integer Linear Programming Model}

The divided classes are used as the input of the mixed integer linear programming model to optimize the milk-run routes of the system. In this paper, a mixed integer linear programming model is used to determine the routes. A milkrun vehicle departs from the depot node and return to the depot node after visiting all suppliers, each supplier is visited at once, and milk-run vehicle cannot be loaded more than capacity. The overall objective is to minimize the total distance of the milk-run route.

\section{Indices}

$N_{0}$ : Set of nodes with depot $(i, j=0,1,2, \ldots \ldots N)$

$N$ : Set of supplier nodes $(i, j=1,2, \ldots \ldots N)$

$V$ : Set of vehicles $(v=1,2 \ldots V)$

Parameters

K: Capacity of vehicles $\left(\mathrm{m}^{3}\right)$

$d_{i}$ : Demand of supplier $i$

$c_{i j}$ : Total distance between supplier $i$ and supplier $j$

$n$ : Number of suppliers

$u_{j}$ : Variable to eliminate the sub tour

$$
\begin{aligned}
& x_{i j v}=\left\{\begin{array}{l}
1 \text { if milk-run vehicle v travels from supplier } i \text { to supplier } j \quad(i \neq j) \\
0 \text { otherwise }
\end{array}\right.
\end{aligned}
$$

\section{$\underline{\text { Model }}$}


$\operatorname{Min} Z=\sum_{i, j \in N_{0}} \sum_{v \in V} c_{i j} x_{i j v}$

$\sum_{i \in N_{0}} \sum_{v \in V} x_{i j v}=1, \quad \forall j \in N$

$\sum_{j \in N_{0}} \sum_{v \in V} x_{i j v}=1, \quad \forall i \in N$

$\sum_{i \in N_{0}} \sum_{j \in N} d_{j} x_{i j v} \leq K, \quad \forall v \in V$

$\sum_{j \in N} x_{0 j v}=1, \quad \forall v \in V$

$\sum_{i \in N} x_{i 0 v}=1, \quad \forall v \in V$

$\sum_{i \in N_{o}} x_{i k v}-\sum_{j \in N_{0}} x_{k j v}=0, \quad \forall k \in N$ and $\forall v \in V$

$x_{i j v} \in\{0,1\}, \quad \forall(i, j) \in N$ and $\forall v \in V$

$u_{i}+1-n\left(1-\sum_{v \in V} x_{i j v}\right) \leq u_{j}, \quad i \neq j$ and $i, j>0$

The objective function (1) seeks to minimize total distance travelled. Constraints (2) and (3) ensure that each supplier node is visited exactly once by one vehicle. The milk-run vehicle capacity is ensured by constraint (4). Constraints (5) and (6) ensure departure from and return to the depot. Constraint (7) ensures the departure from the visited node. Constraint (8) defines the binary decision variables. Constraint (9) eliminates sub-tours.

\section{B. Container Loading Heuristic}

Container loading problem (CLP) is the problem of loading a subset of rectangular boxes into a rectangular container of fixed dimensions such that the volume of the packed boxes is maximized [21]. [22] studied the CLP since the middle 1960s and many algorithms, for the solution of the classes of the CLP, had been developed. CLP is a very complex combinatorial problem and, for this reason, an optimal solution (in a reasonable time) does not exist. So, the proposed algorithms are based onto a dynamic programming, a heuristic or a combination of them, achieving a good sub-optimal solution in a reasonable time [3].

The aim of the container loading heuristic developed in this study is, to increase the utilization of container loading. The manufacturer has two different milk-run vehicles: truck with $37,20 \mathrm{~m}^{3}$ capacities and with $72,27 \mathrm{~m}^{3}$ capacities. The logistics department has five different boxes with different sizes. If boxes are not same sized, the manufacturer cannot load the box over the preceding box. Thus, the developed heuristic algorithm gets over this problem. If the size of subsequent box is same as the preceding box, and the height of the boxes are not bigger than the height of the milk-run vehicle, the heuristic algorithm loads the subsequent box on the preceding box. If the size of the box is not same and/or the height of the boxes is bigger than the height of the milkrun vehicle, the algorithm loads the subsequent box at the length of the preceding box. This loading procedure proceeds to the length of the milk-run vehicle. When the loading procedure reaches at the length of the milk- run vehicle, the algorithm loads the subsequent box at the width of the milk-run vehicle. If the remaining space is not sufficient for the subsequent box, the algorithm starts loading to a new milk run vehicle. The flow-chart of the container loading heuristic algorithm can be seen in Figure 3.

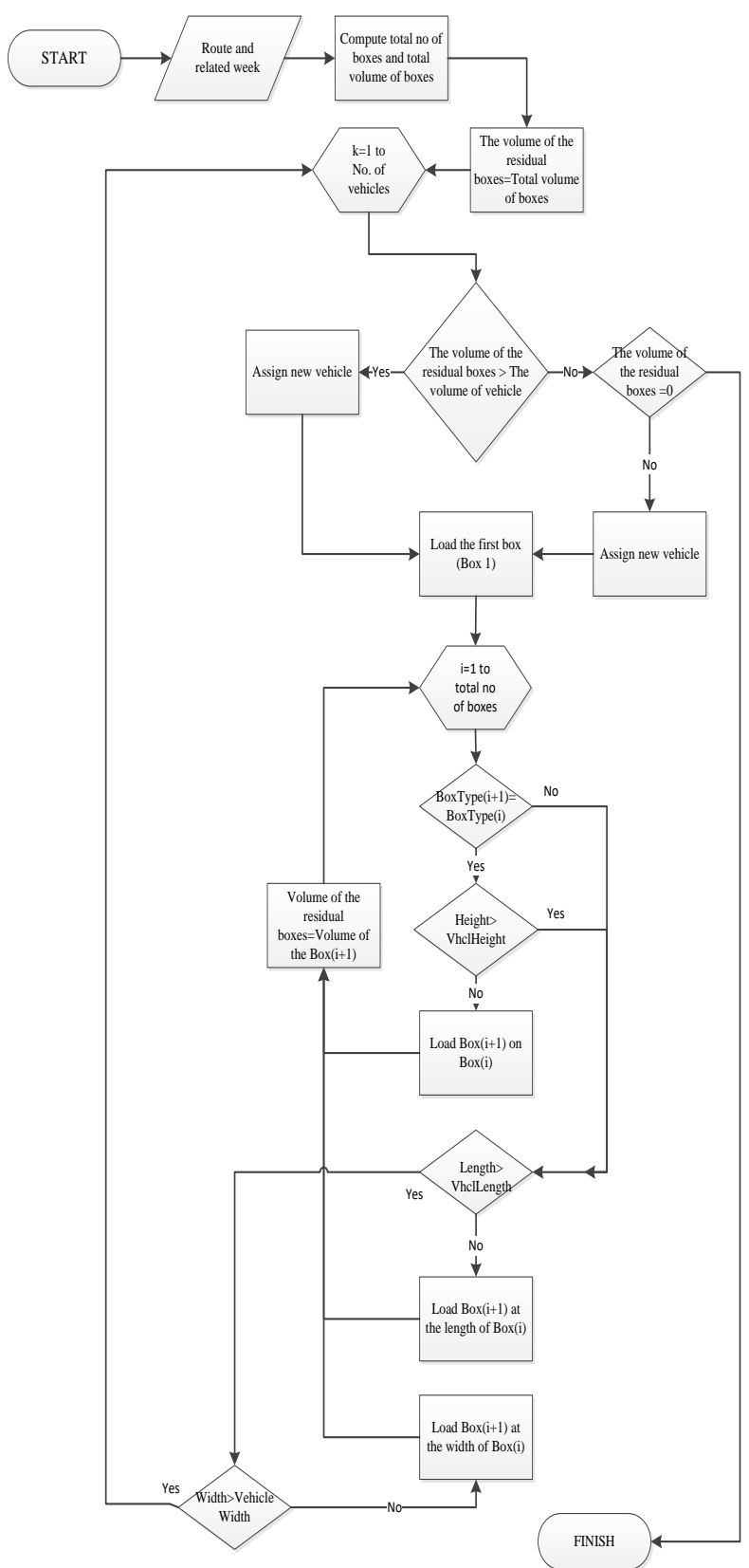

Fig.3. The flowchart of the proposed container loading heuristic algorithm

\section{Time-interval Assignment Heuristic}

Time-interval assignment heuristic algorithm assigns milk-run vehicles to the depots, considering the cycle time and the service time of the milk-run route. The algorithm tries to minimize the coincidence at the depots.

\section{APPLIED SOLUTION PROCEDURES}

The main steps of the proposed approach can be summarized as follows:

-Construction of optimal milk-run routes, considering monthly demand, 
-Increase the utilization of milk-run vehicles with container loading heuristic algorithm,

-Assignment of time-interval to the milk-run vehicles for unloading process by avoiding the vehiclecoincidence at the depots.

The cluster analysis is performed for 54 suppliers and 6 different classes are established. The mixed integer linear programming model is solved by using Mathematical Programming Language (MPL) for each class, by considering monthly demand of the suppliers and distances. Two milk-run vehicles for Class_1, four milk-run vehicles for Class_2, three milk-run vehicles for Class_3 and Class_4, two milk-run vehicles for Class_5 and Class_6 are assigned to the routes. Container loading heuristic algorithm developed with Visual Basic loads the boxes to the relevant milk-run vehicles and checks the results of the mathematical programming model. For example, mathematical model assigns two vehicles to the Class_1, if the loading heuristic cannot load all of the boxes to the two milk-run vehicles, the algorithm increases the number of milk-run vehicles and the mathematical model seeks new optimum point. Time interval assignment heuristic developed with Visual Basic is the last stage of the procedure. The algorithm takes into account the number of milk-run vehicles, cycle time of the routes and the service time of the routes. This algorithm seeks to avoid the coincidence of the milk-run vehicles while visiting the depots.

The user interface depicted in Figure 4, is developed to simplify the usage of the procedures. The data related to demand and distance matrices of the suppliers can be read over Excel files. The user pushes to "Route Constructor" button, to determine the optimal routes of the milk-run vehicles. The number of suppliers involved in each classes and the required total number of milk-run vehicles can also be seen on main screen. Container loading button proceeds the container loading algorithm, and the user can see container loading screen depicted in Figure 5. This screen contains detailed info about the loading of milk-run vehicle, such as, loading average and loading efficiency.

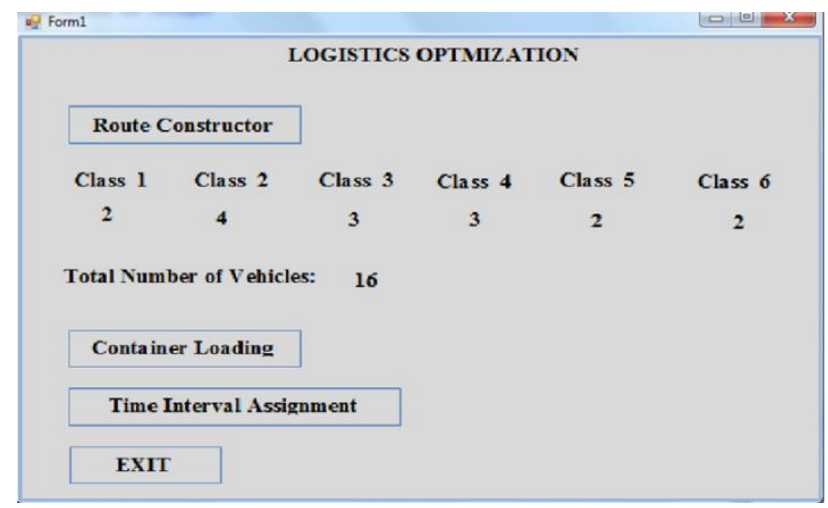

Fig.4. The main screen of the logistics optimization interface

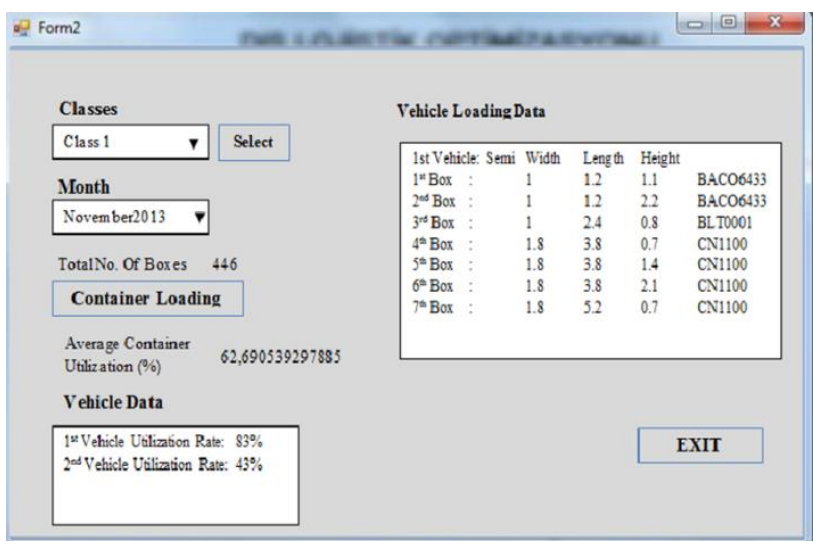

Fig. 5.Container loading screen of the logistics optimization interface

Time interval assignment button in Figure 4 is related to time interval assignment procedure. The user can see and also take a print out of the milk-run vehicles visiting time to the depots, as shown in Figure 6.

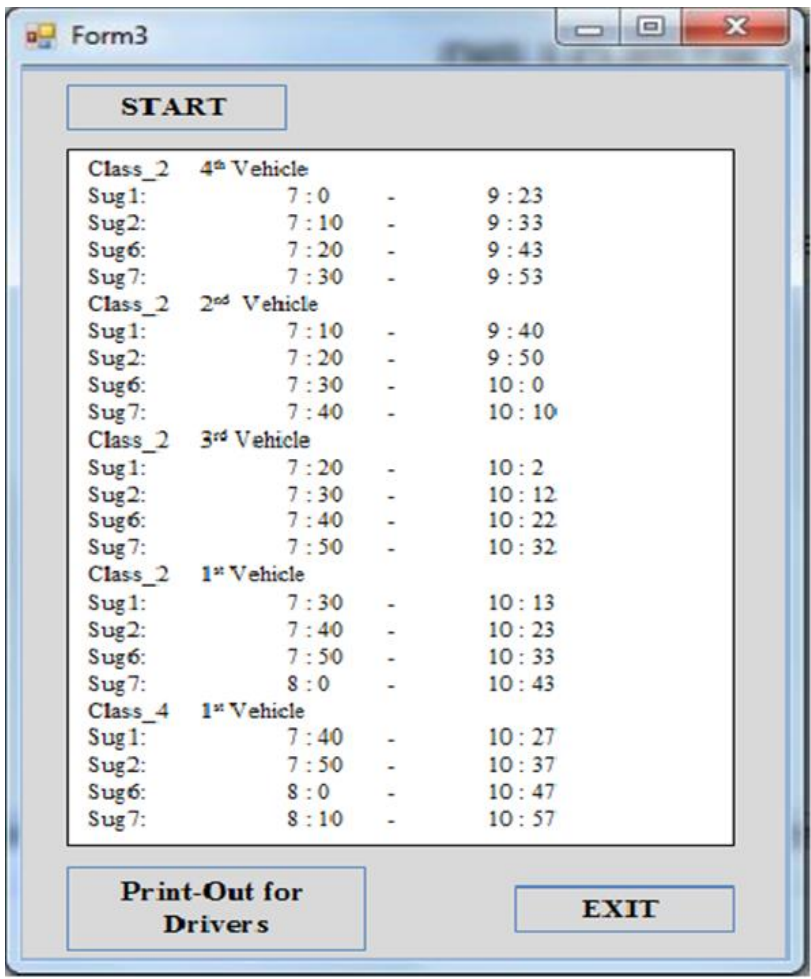

Fig.6.Time-interval assignment screen of the logistics optimization interface

\section{CONCLUSIONS AND DISCUSSION}

This paper aims to solve the real life problem of an automotive equipment manufacturer. The contribution of this study is multiple. Initially the study aims to minimize the fluctuations of the number of milk-run vehicles between workdays and production facilities. To overcome this problem, the milk-run routes analyzed and optimal milk-run routes are determined for 54 suppliers by mixed integer linear programming model. The variations of number of milk-run vehicles for different workdays and production facilities for the proposed system can be seen in Figure 7. Also, the total number of milk-run vehicles was 578 for the current system, and after determining the optimal routes, the 
proposed system requires 480 vehicles to carry same amount of load.

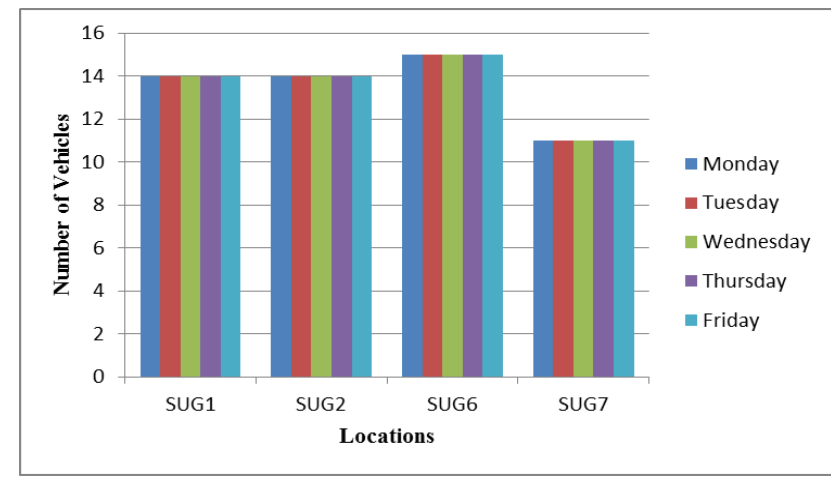

Fig. 7. Number of vehicles of the proposed system

The second procedure aims to increase container utilization of the milk-run vehicles. The average loading rate of the milk-run vehicles was $43.75 \%$, after applying the container loading heuristic algorithm, the loading rate increases to $70.57 \%$. The third problem was the coincidence of the milk-run vehicles while visiting the depots. Timeinterval assignment algorithm seeks to avoid the coincidence of the milk-run vehicles. In the current system, the milk-run vehicles were waiting almost 10 minutes at the depots (for the departure of the precedence milk-run vehicle). The suggested system avoids this waiting time by constructing a time table for each vehicle, including the visiting time for the depots.

\section{ACKNOWLEDGMENT}

The authors thank the manufacturer for providing data for the problem. This study was conducted as an Integrated System Design Project, in Uludag University Industrial Engineering Department, instructed by Prof. Dr. Nursel Öztürk and Assist. Prof. Dr. Asli Aksoy. The authors are grateful to work with students Huriye Yalçın, Yasin Taksim and Samet Çalışkan during this project.

\section{REFERENCES}

[1] M. Christopher, New directions in logistics (5th ed), London, GBR (Chapter 2), 2006.

[2] W. Ho, G.T.S. Ho, P. Ji and H.C.W. Lau, "A hybrid genetic algorithm for the multi-depot vehicle routing problem", Engineering Applications of Artificial Intelligence, vol. 21, pp. 548-557, 2008.

[3] D. Aprile, J. Egeblad, A.C.S. Garavelli Lisi and D. Pisinger, Logistics optimization: Vehicle routing with loading constraints presented at the 19th International Conference on Production Research, Valparaiso, Chile, 29 July- 2 August 2007.

[4] G.B. Dantzig and R.H Ramser "The truck dispatching problem", Management Science, vol. 6, pp. 80-91, 1959.

[5] B. Golden, and A. Assad, Vehicle routing: Methods and studies, North-Holland, Amsterdam, 1998.

[6] G. Laporte "The vehicle routing problem: An overview of exact and approximate algorithms", European Journal of Operations Research, vol. 59, pp. 345-358, 1992.

[7] L. D. Bodin "Twenty years of routing and scheduling", Operational Research, vol. 38, no. 4, pp. 571-579, 1990.

[8] $\mathrm{P}$. Toth and D. Vigo, The vehicle routing problem, SIAM. Philadelphia: PA, 2002.
[9] H. Nazif, and L.S. Lee "Optimised crossover genetic algorithm for capacitated vehicle routing problem", Applied Mathematical Modelling, vol. 36, pp. 2110-2117, 2012.

[10] G. Laporte, M. Gendreau, J.Y. Potvin and F. Semet "Classical and modern heuristics for the vehicle routing problem", International Transactions in Operations Research, vol. 7, pp. 285-300, 2000.

[11] J.F. Cordeau, M. Gendreau, G. Laporte, J.Y. Potvin, and F. Semet, "A guide to vehicle routing heuristics", Journal of the Operational Research Society, vol. 53, pp. 512-522, 2002.

[12] É. Taillard "Parallel iterative search methods for vehicle routing problems", Networks, vol. 23, no.8, pp. 661-673, 1993.

[13] G. Barbarosoglu, and D. Ozgur "A tabu search algorithm for the vehicle routing problem", Computers \& Operations Research, vol. 26, pp. 255-270, 1999.

[14] P. Toth, and D. Vigo "The granular tabu search and its application to the vehicle routing problem", INFORMS Journal on Computing, vol. 15 , pp. 333-348, 2003.

[15] I.H. Osman "Meta strategy simulated annealing and tabu search algorithms for the vehicle routing problem", Operations Research, vol. 41, pp. 421-451, 1993.

[16] B. Bullnheimer, R.F. Hartl, and C. Strauss "An improved ant system algorithm for the vehicle routing problem", Annals of Operations Research, vol. 89, pp. 319-328, 1999.

[17] D. Mester, and O. Bräysy "Active guided evolution strategies for large-scale capacitated vehicle routing problems", Computers \& Operations Research, vol. 34, pp. 2964-2975, 2007.

[18] A. Bortfeldt, and H. Gehring, "A hybrid genetic algorithm for the container loading problem", European Journal of Operational Research, vol. 131, no.1, pp.143-161, 2001

[19] A. Moura, and J.F. Oliveira "A GRASP approach to the Container Loading Problem", IEEE Intelligent Systems and Their Applications, vol. 20, no. 4, pp. 50-57, 2005.

[20] S.C. Liang, C.Y. Lee, and S.W. Huang "A hybrid meta-heuristic for the container loading problem", Communications of the IIMA, vol. 7,no. 4, pp. 73-84, 2007.

[21] D. Pisinger "Heuristics for the container loading problem", European Journal of Operational Research, vol. 141, no. 2, pp. 382-392, 2002.

[22] P.C. Gilmore, and R.E. Gomory "Multi-stage cutting problems of two and more dimensions", Operational Research, vol. 13, pp. 94119,1965 .

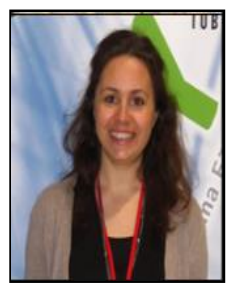

Aslı Aksoy is as an Assistant professor at the Industrial Engineering Department, Uludag University, Turkey. She received bachelor, MSc and $\mathrm{PhD}$ degrees from Uludag University, Her research interests include supply chain planning and optimization, decision making methods, artificial intelligence techniques and heuristic algorithms.

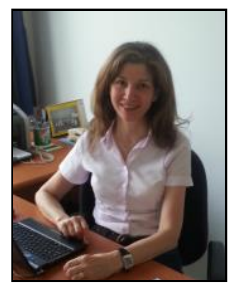

Nursel Öztürk is a Professor at the Industrial Engineering Department, Uludag University, Turkey. She received her BS degree in Chemical Engineering from Hacettepe University. She joined Uludag University in 1990 after working in the industry and Turkish Standards Institution. She holds a Master's degree in Business Administration from Uludag University and she received her $\mathrm{PhD}$ in Industrial Engineering from İstanbul Technical University. Her research interests include manufacturing systems, lean production, artificial intelligence, artificial neural networks, decision making techniques, optimization, heuristics algorithms, green logistics and supply chain management. 